眖水成陆，并向湖域推进，发育成三角洲平原。在 TM3、4、5 波段组合的国像上,三角洲呈 蓝绿色调。其水系发育, 呈放射状，农田的结构顼其自然水系而排列。由于耕作历史㤵久, 其土境质地盵沃，农作物长势极好。植被覆盖密集的部分、图像呈深绿色调。

围湖星殖区是人工将古丹旧湖围成陆地的区域。其农田虽几经苍桑 , 但在图像上其人 为千硕之痕迹仍依稀可见。其一, 是以圩为单位的规则形围星区。图像上可以看到,农田 间的水系结构多为人工开丵而成的规则形水网，农田依水网而排列，亦呈矩形结构（见图 $2 a 、 2 b)$ 。其二, 是以残存的零星湖荡为中心的环形围星区。图像上可以看到, 凡环形结构 的中心部位都有一个残存的小湖荡, 围绕小湖荡通常有一些小的环形水系分布、其外围有 一大的环形河道与外界相连。环形围星区在图像上还清晰地显示,一条条小的河沟,自边 缘向湖荡中心廷伸汇集，农田便沿畕水系由边缘向湖心分布，多呈条带状结构（见图 2c)。 这种图像结构表明,当年围是是以湖荡为中心,由四周向中心展开的。上述两种人工围星 的农田的土质较三角洲平原要差, 农田地势较低。地下水位高, 图像呈深蓝绿色, 间有㷋红 色。

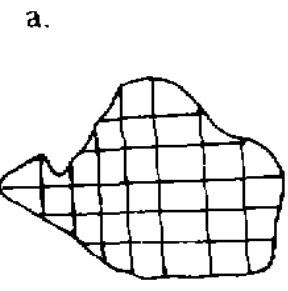

a. 现代围量水乘之一
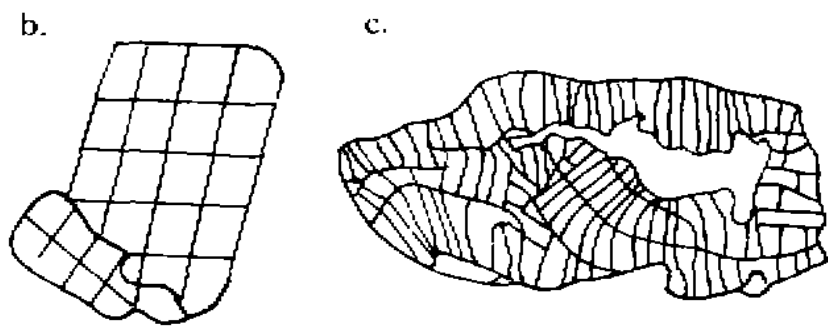

图 2 不同围星型的水系结构

Fig. 2 The structure of stream system in the different reclamation type

（2）历史围星与现代围旺农田的影像差异

早期的围湖星殖距今已有数干年的历史.由于当时社会生产力和生产关系的限制,其 农田的田块规模都比较小。这种类型的水系有的是以圩为单位的规则型,有的是绕残存的 湖泊而排列的环状。由于这部分农田已有较长的制作史，土㙲有机质含量较高，作物长势 亦好。在遭感图像上,植被覆盖率比现代围筀的农田高,色调深.密度大。

现代围是的土地、由于是在一个特定的历史条件和社会经济条件下产生的,农田及其 水系结抅与古代圈星有较大的差异、农田田块普遍较大,特别是一些农场,不仅田块大,而 且田块的结构都非常标准。如丹阳湖农场，其所有田块都是按南北方向排列的, 人工沟渠 纵措之间互相垂直，整产规范。在䧟感图像上,水系呈深蓝色网格扰分布，农田亦呈规则状 排列，不同的农作物长势差异显示为不同深浅的黄绿色和红色。

\title{
2. 用动态对比法分析古丹阳湖的演变与消亡
}

动态对比法包含不同年你、不同季节的遥感图像之间进行的对比分析.遥感图像与地 图等其他非遥感资料之间的对比分析。

(1)古丹阳湖的游积和分解时期 
表 1 不同暴变类型遭感影像分析

Tab. I The image features analysis of different evolution types

\begin{tabular}{|c|c|c|c|c|c|c|}
\hline \multirow[b]{2}{*}{ 类 型 } & \multicolumn{2}{|c|}{ 色 调 } & \multirow[b]{2}{*}{ 水系结构 } & \multirow[b]{2}{*}{ 水系特点 } & \multirow[b]{2}{*}{ 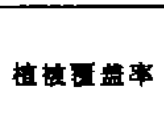 } & \multirow[b]{2}{*}{ 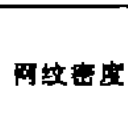 } \\
\hline & $\begin{array}{c}\text { TM } \\
\text { 3.4.5 桋段 }\end{array}$ & $\begin{array}{c}\text { MSS } \\
4.5 .7 \text { 诐居 }\end{array}$ & & & & \\
\hline 三角洲平原 & 蓝绿 色 & 红 & 放射状 & 自然形态 & 很高 & 太 \\
\hline 历史国量 $(一)$ & 深蓝绿色 & 暗竍色 & 短 形 & 以圩为单位与外界相连 & 高 & 软大 \\
\hline 历史国量(二) & 深蓝绿色 & 鉭红色 & 环形络构 & 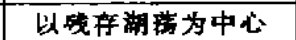 & 高 & 软大 \\
\hline 理代国星 & 浅堁色 & 鲜红色 & 规则矩形 & 以圩为单位与外眾相这 & 较低 & 小 \\
\hline
\end{tabular}

湖泊因受地质、地貌、水文、气象等内外营力的作用、不断演变、从发生、发展直至消 亡、是受自然规律所支配的。在气候湿润、雨量充沛的水阳江、育戈江流域，导致湖泊演变 的重要因素是水量补给的变化和泥沙的淤积，同时也受着人类活动的强烈影响。水阳江、

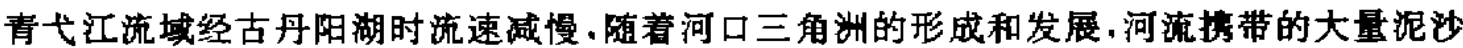
在湖中沉积, 湖盆逐年为大量泥沙所覆盖。原湖盆局部地形上的差异和沉积物分布不均 匀,导致了古丹阳湖在历史进珵中不断变浅,分解成大小不一的众多湖莎。丹阳湖、石白 湖、固城湖就是在古丹阳湖解体过程中产生的 ${ }^{\mathbb{D}}$ 。由于卫星䧟感资料 70 年代才有,因此这 一时期的变化情况主要是根据古文字资料,并参考了现代遥感图像解译而成的。凡冲积深 积较早的,图像色调较浅,且植被茂密; 凡冲积㵀积较晚的,图像上色调较深,植被较稀疏, 地下水位较浅。

(2)历史围垦时期

3000 多年前的春秋初期.古丹阳湖被泥沙㵀积而分解,在自然和人为活动的双重因 素作用下发生着剧烈的变化。一方面、河流上游继续㩲带泥沙入湖,使湖泊深积; 另一方 面, 人为的围暴加速了湖泊演变、消亡的进程。据有关县志记载,公元前 514-476 年,人类 就在该湖区开馓围湖㫢殖活动,到宋朝时,围湖暴殖活动进入鼎盛时期。以固城湖为例,自 公元前 514 年至公元 1279 年,共围湖 $156 \mathrm{~km}^{2}$,仅宋就围湖 $105.1 \mathrm{~km}^{2}$,占湖泊面积的 $50 \%$ 。这一时期,古地图在解译过程中起了重要作用。有些地名是一种历史记载的反映， 如相国圩、大官圩等。这些圩在遥感图像上都清晰可辩，其水系完䇥，自成体系，地块细密 呈淡蓝绿色调，其间有星星点点的红色分布，则是分散的居民点。

（3）现代围星时期

本时期主要是依靠不同年代的卫星图像的对比分析而进行研究的。

50 年代以来,围湖暴殖活动使湖泊面积再一次缩小。从遗感图像上可以看到, 1977 年 以前固城湖北部建立了跃进、永联、双塔三个圩、面积 18500 亩左右,而仅 1977 年到 1979 年的两年中就围湖 41400 亩。从 60 年代至 80 年代初,固城湖的被围㫢面积达 $40.5 \mathrm{~km}^{2}$, 蓄水面积再一次缩减，据江苏省水利部门反映、该湖低水位时的蓄水容量已不能清足工农 业用水高峰时的需要，有时不得不设法从石目湖调水补充。在石臼湖的南岸和北岸共围湖 $10.7 \mathrm{~km}^{2}$ 。丹阳湖的围旺规模更大,从 60 年代至 70 年代,围湖面积达 $143 \mathrm{~km}^{2}$,昔日姻波浩 游之大湖已不复存在，仅留下了一弯 $18 \mathrm{~km}^{2}$ 的水道。据有关资料记载, 1916 年固站、石白、 丹阳三湖的总面积为 $519.7 \mathrm{~km}^{2}$ ，至 1980 年,已缩小为 $243.5 \mathrm{~km}^{2}$ 。仅 60 年时间, 湖面就缩 
小了一半以上。

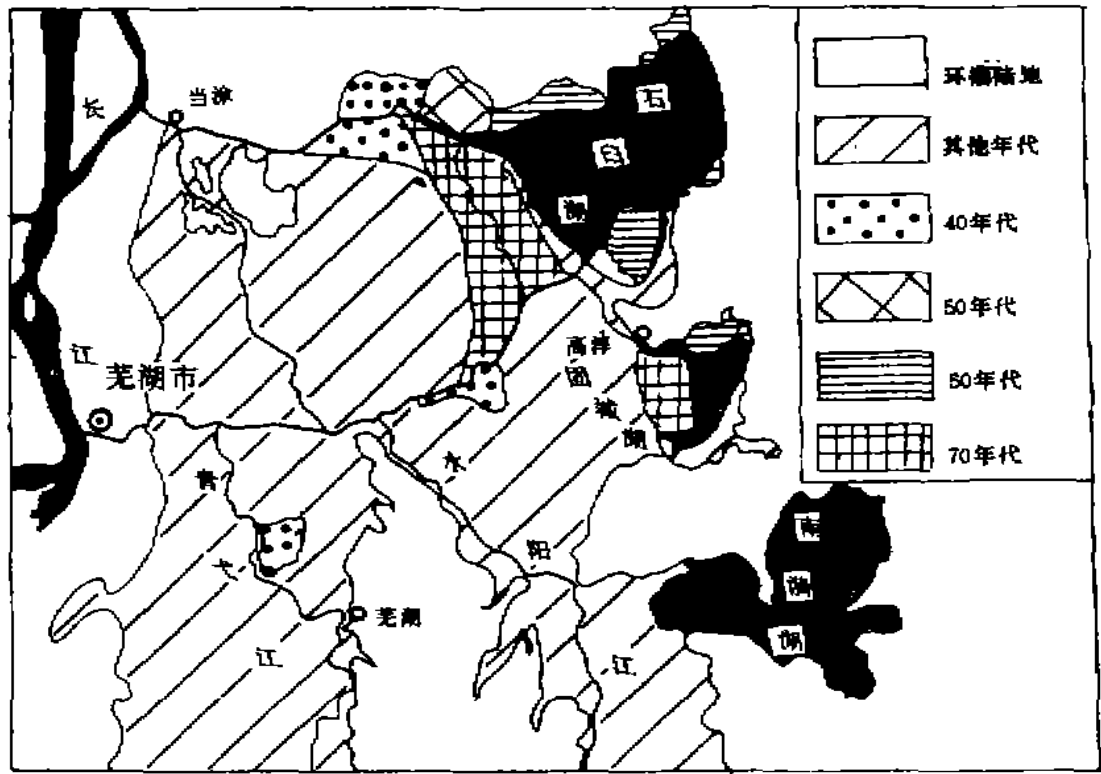

困 3 各个时期的围暴范雷

Fig. 3 The reclamation range in different period

\section{三、古丹阳湖演变的后效分析}

古丹阳湖自形成以来、从淤积、分解直至消亡、经历了数干年的历史、而人类对湖泊的 围旺加速了湖泊演变的进珪。这种演变必然导致湖泊功能、生态系统等发生一系列的变 化。

\section{1. 湖泊面积不断缩小,调萻功能下降}

古丹阳湖上游来水面积 $80 \%$ 以上是山丘地带、每年讯期,上游来水大而狧,古丹阳湖

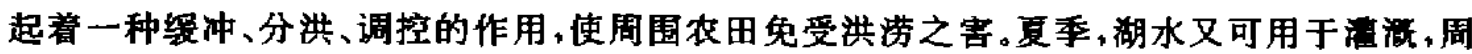
围农田广为受益。随着湖泊的不断矤积和围㫢、湖泊客量随之減少、汛期不能充分发挥其 调洪的作用：而自成体系的坶区水系严重影响着水流的下泄、每到大水年份，许多圩区难 兔遭受洪涝之害。如 1991 年臬季出现的百年不遇的大水、湖区人民遭受了极大的损失。据 南京日报载: 仅高淳一县, 受灭面积就达 40 多万亩、死亡 2 人.伤 10 人, 倒塌房屋 1205 间，许多工厂被迫停产，直接经济损失达 1.5 亿元。

\section{2. 湖泊生态环境日趋恶化}

石目湖、丹阳湖、固城湖原均为水生植物生长茂盛的湖泊,湖区气候温和湿洞、滩地发 育良好, 适宜于水生植物的生长。大片芦苇、芳草生长茂密、其中还间杂生长着浑叶植物和

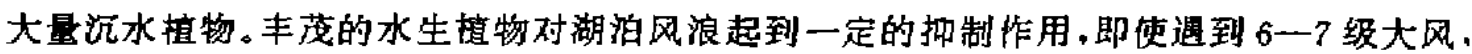
渔民仍然可以在湖区捕掿。由于各个湖泊之间互相连通，并与长江相通，春夏季节，大量鱼 


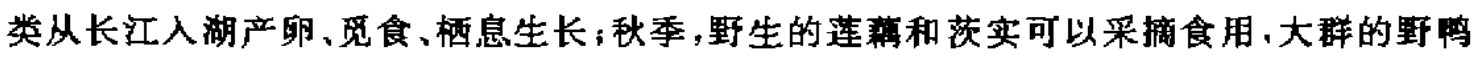
栖息于湖滩，湖中渔业资源极为丰富，常见鱼种有60多种。随着湖泊的族积和围圼，特别 是丹阳湖的消亡,对湖泊生态环境影响很大,大片的芦苇和草草滩地菠围暴，芦苇、荠草产 量剧减，渔业资源也因此遭受破坏，鱼产量急剧下降，品种日道减少，湖区人民经济牧入橆 到影响。湖中的水生植物是一种很好的肥源，湖区有几万亩农田需要依靠水生植物作其肥 料, 目前已不能满足需要。原用于手工艺编织的芦苇产量已供不应求,需要从外地调进 ${ }^{[1]}$ 。

\title{
四、结语
}

综上所述,泥沙谈积是古丹阳湖演变的主要原因, 而人类大规模的围湖是殖活动加速 了它的演变和消亡。古丹阳湖的演变改变了湖区的生态环境, 又直接影响着湖区人民的生 活。

遥感信息具有宏观、动态、如实地记录地面实况的优点,运用多时相遥感信息复合进 行湖泊演变研究，具有省时、省力、定位准确、超越时空界限等优点。

运用多种遥感图像处理方法,可以提取不同的湖泊环境特征,有利于湖泊演变研究， 它无薙是湖泊生态环境监测的良好工具。

$$
\text { 考文融 }
$$

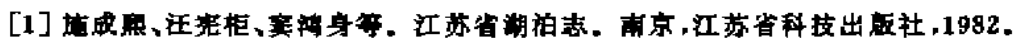

\section{AN APPLICATION OF REMOTE SENSING TECHNIQUES IN THE STUDY OF PALAEO-DANYANG LAKE EVOLUTION}

\author{
Dai Jinfang Zhao Rui \\ (Nanjing Imstitute of Geography \& Limmalogy, Academia Sinica , Nanjing 210008)
}

\begin{abstract}
Applying the method of remote sensing image process suitable for lake evolufion study, with the structure, lamination, color cast of 1 emote sensing images, the features and differen of remote sensing image between different types of the lake evolution were discussed.

Based on the lake environmental information from the technique of remote sensing, together with the manifold historical map and consequence of data, the origin and law of the lake evolution were analysed in this paper.

The resoult shows that this kind of researching method is suited to the lakes in East China.
\end{abstract}

Key Words lake evolution, reclamation works, remote sensing image processing 